\title{
Optimal medical therapy for secondary prevention after an acute coronary syndrome: I8-month follow-up results at a tertiary teaching hospital in South Korea
}

Hee Ja Byeon ${ }^{1, *}$

Young-Mo Yang ${ }^{2, *}$

Eun Joo $\mathrm{Choi}^{2}$

'Department of Pharmacy, Chosun University Hospital, ${ }^{2}$ Department of Pharmacy, College of Pharmacy, Chosun University, Gwangju, South Korea

*These authors contributed equally to this work

\author{
This article was published in the following Dove Press journal: \\ Therapeutics and Clinical Risk Management \\ 12 February 2016 \\ Number of times this article has been viewed
}

Background: Acute coronary syndrome (ACS) is a fatal cardiovascular disease caused by atherosclerotic plaque erosion or rupture and formation of coronary thrombus. The latest guidelines for ACS recommend the combined drug regimen, comprising aspirin, $\mathrm{P} 2 \mathrm{Y}_{12}$ inhibitor, angiotensin-converting enzyme inhibitor or angiotensin II receptor blocker, $\beta$-blocker, and statin, at discharge after ACS treatment to reduce recurrent ischemic cardiovascular events. This study aimed to examine prescription patterns of secondary prevention drugs in Korean patients with ACS after hospital discharge, to access the appropriateness of secondary prevention drug therapy for ACS, and to evaluate whether to persistently use discharge medications for 18 months.

Methods: This study was retrospectively conducted with the patients who were discharged from the tertiary hospital, located in South Korea, after ACS treatment between September 2009 and August 2013. Data were collected through electronic medical record.

Results: Among 3,676 patients during the study period, 494 were selected based on inclusion and exclusion criteria. The regimen of aspirin + clopidogrel $+\beta$-blocker + angiotensin-converting enzyme inhibitor/angiotensin II receptor blocker + statin was prescribed to 374 (75.71\%) patients with ACS at discharge. Specifically, this regimen was used in 177 (69.69\%) unstable angina patients, 44 (70.97\%) non-ST-segment elevation myocardial infarction patients, and 153 (85.96\%) ST-segment elevation myocardial infarction patients. Compared with the number of ACS patients with all five guideline-recommended drugs at discharge, the number of ACS patients using them 12 ( $n=169$, $34.21 \%)$ and 18 ( $n=105,21.26 \%)$ months after discharge tended to be gradually decreased.

Conclusion: The majority of ACS patients in this study received all five guideline-recommended medications at discharge from the hospital. However, the frequency of using all of them had been gradually decreased 3, 6, 12, and 18 months after discharge compared with that at discharge. Careful monitoring of adherence on ACS secondary prevention medications may help improve the outcomes of ACS patients in terms of recurrent ischemic cardiovascular events.

Keywords: acute coronary syndrome, secondary prevention, guideline adherence, patient discharge, electronic medical record, cardiovascular disease

\section{Introduction}

Acute coronary syndrome (ACS) is a serious cardiovascular disease, which is usually caused by atherosclerotic plaque erosion or rupture and subsequent coronary thrombus formation due to platelet activation. ${ }^{1,2}$ ACS is classified into three different types: unstable angina (UA), non-ST-segment elevation myocardial infarction (NSTEMI), and ST-segment elevation MI (STEMI). ${ }^{3} \mathrm{UA}$ is referred to as the presence of ischemic symptoms without an increase in biomarkers and shows a transient change in
Department of Pharmacy, College of

Pharmacy, Chosun University, 309

Pilmun-daero, Dong-gu, Gwangju 6I452,

South Korea

$\mathrm{Tel}+82622306382$

Fax +82622225414

Email ejchoi@chosun.ac.kr 
electrocardiogram. ${ }^{3}$ The term MI is employed to indicate myocardial necrosis in the condition of acute myocardial ischemia. ${ }^{3}$ NSTEMI and STEMI are distinguished according to whether to present persistent ST-segment elevation on electrocardiogram. ${ }^{3}$

According to the latest ACS guidelines and clinical trials, it is strongly recommended to follow the ACS treatment guidelines in order to prevent the recurrence of ischemic diseases and to improve the quality of life in patients discharged from hospitals after ACS treatment. ${ }^{4-6}$ The American Heart Association/American College of Cardiology guidelines published in 2014 recommend the long-term prescription of the combined drug regimens, including aspirin, $\mathrm{P}_{2} \mathrm{Y}_{12}$ inhibitor, angiotensin-converting enzyme inhibitor (ACE-I) or angiotensin II receptor blocker (ARB), $\beta$-blocker, and statin, in discharging patients after the completion of ACS treatment. ${ }^{4}$ In particular, early initiation of reperfusion by using either thrombolytic therapy or percutaneous coronary intervention (PCI) in patients with STEMI is necessary to reduce myocardial infarct size and to enhance a survival rate. ${ }^{7-9}$

In case the recommended drugs (eg, aspirin, ACE-I, $\beta$-blocker, and statin) were persistently administered to ACS patients, the risk rate of future cardiovascular diseases and death would be likely to decrease by $75 \%$ within 2 years after ACS incidence. ${ }^{6,10}$ In the study conducted by Allonen et al, ${ }^{11}$ the mortality rate of ACS patients who had regularly taken statins was reduced by nearly three times as compared with that of ACS patients who had not taken statins (4.9\% vs $14.9 \%$ ). Especially, the cardiovascular-related mortality rate was $2.9 \%$ in ACS patients with statins regularly administered, whereas the rate was $7.4 \%$ in those who had not taken statins. In the 1-year follow-up study conducted with 5,833 ACS patients by Yan et al, ${ }^{12}$ the mortality rate after 1 year was significantly reduced in ACS patients discharged with antiplatelet or anticoagulant, $\beta$-blocker, ACE-I, and statin as compared with ACS patients discharged without them (odds ratio: $0.54 ; 95 \%$ confidence interval: $0.36-0.81 ; P=0.003)$. Additionally, Bi et $\mathrm{al}^{13}$ reported that the recommended drug use rates in patients with acute MI or UA pectoris were high at discharge, but those were gradually decreased after 6 and 12 months.

The morbidity and mortality rates of ACS patients due to atherosclerotic plaque erosion or rupture can be reduced with the uses of antithrombotic agents and early revascularization. ${ }^{1}$ Aspirin is a basic antithrombotic agent to be prescribed to patients with ACS, and $\mathrm{P} 2 \mathrm{Y}_{12}$ receptor inhibitors such as clopidogrel, prasugrel, and ticagrelor are also prescribed to ACS patients as single or combined antithrombotic agents. ${ }^{1}$ Besides these drugs, anticoagulants such as bivalirudin, unfractionated heparin, enoxaparin, and fondaparinux are administered to patients with ACS. ${ }^{1}$ For example, in case of using enoxaparin in patients with ACS, the incidence rates of death, reinfarction, and recurrent angina were reduced after 30 days from $21 \%$ to $13 \%(P=0.03) .{ }^{14}$

So far, almost all of the studies regarding discharge medication patterns and their follow-up evaluations after ACS treatment were conducted in foreign countries, and these studies were usually followed up until 12 months. . $^{6,10-13,15-21}$ However, to our knowledge, similar studies have rarely been implemented in Korea. Thus, the objectives of this study were to examine prescription patterns of secondary prevention drugs in ACS patients after hospital discharge, to access the appropriateness of secondary prevention drug therapy for ACS, and to evaluate whether to persistently use discharge medications for 18 months.

\section{Methods}

Ethical approval for the study was received by the Institutional Review Board of Chosun University Hospital (CHOSUN 2014-10-015). Informed consents were not acquired from the study patients because their data were deidentified and encoded anonymously before analysis. This study was implemented retrospectively with the patients who were discharged from the same hospital after ACS treatment between September 2009 and August 2013. Chosun University Hospital is a tertiary health care institution located at Gwangju in South Korea, and it is equipped with 715 beds.

\section{Study population}

Among patients who were diagnosed with UA, NSTEMI, or STEMI during the study period and were discharged after ACS treatment, those who had outpatient clinic visits as part of routine care and met the following inclusion criteria were selected for this study: patients with $\geq 18$ years of age and patients who had prescription information of ACS medications at discharge and 3, 6, 12, and 18 months after discharge..$^{5,15}$ However, the following exclusion criteria were applied: patients who were not diagnosed with ACS at hospital admission, patients whose types of ACS were not recorded, patients without prescription information at discharge, patients who died during hospitalization, patients who were transferred from other hospitals, patients who did not have acute or current clinical symptoms, patients with secondary infarction due to anemia, and the same patients who were readmitted to the hospital during the study period. ${ }^{5,6,15,22}$

\section{Data collection and processing}

Through retrospective chart review of electronic medical records (EMRs) of patients, the following information 
was collected by a trained hospital pharmacist with paper case report forms: demographic characteristics (eg, date of birth, age, sex, height, weight, body mass index, and types of ACS), risk factors for ACS (eg, diabetes, hypertension, hyperlipidemia, renal failure, current smoker, family history, and obesity), underlying diseases (eg, MI, heart failure [HF], coronary artery bypass graft, PCI, transient ischemic attack, and stroke), and prescribed medications (eg, aspirin, clopidogrel, $\beta$-blocker, ACE-I or ARB, and statin) at discharge and during the follow-up period. ${ }^{5,15,22,23}$

In this study, the adherence of ACS guidelines to medications was defined as the combined prescription of the following five drugs: acetylsalicylic acid, P2Y inhibitor, $\beta$-blocker, ACE-I or ARB, and statin., ${ }^{4,8}$ From the EMRs, information with regard to the prescription of them was abstracted at discharge and 3, 6, 12, and 18 months after discharge. When assessing the prescription at each time point, only prescription information available was collected. Since the pharmacists in the hospital were not allowed to fully access the EMRs of patients, information about contraindications to antiplatelet therapy (eg, active peptic ulceration and bleeding disorders), $\beta$-blocker (eg, bradycardia, hypotension, and uncontrolled HF), ACE-I or ARB (eg, angioedema and renal artery stenosis), and statins (eg, allergy) could not be obtained.22 Any additional contraindications documented by the treating clinicians in the EMRs could not be recorded.

\section{Statistical analysis}

Demographic variables and clinical characteristics of patients selected in this study as well as prescribing rates were examined using descriptive statistics. Frequencies (n) and percentages (\%) were utilized to present categorical variables, whereas mean and standard deviation were used for continuous variables. Chi-square test or Fisher's exact test was performed to assess the differences in proportions. Student's $t$-test or Wilcoxon rank sum test and analysis of variance test or Kruskal-Wallis test were used to compare means for between groups. However, before comparing means between groups, Shapiro-Wilk test was conducted in order to determine the normality of data. All analyses were performed using SAS, version 9.3 (SAS Institute Inc., Cary, NC, USA). $P<0.05$ was considered to be statistically significant.

\section{Results}

A total of 3,676 patients were hospitalized during the study period; 494 ACS patients met the inclusion and exclusion criteria and were included in the analysis (Figure 1). Table 1 summarizes the characteristics of ACS patients participating in the study. Three hundred and twenty-seven (66.19\%) patients were males and $167(33.81 \%)$ were females. The mean age of total patients was $67.71 \pm 10.92$ years. Those patients with UA, NSTEMI, and STEMI were 68.17 \pm 10.48 , $70.69 \pm 10.54$, and $66.01 \pm 11.43$ years, respectively. There was a statistically significant difference in age between three groups $(P=0.0077)$. According to the analysis of risk factors for ACS, hypertension was reported in 306 (61.94\%) patients, diabetes in 199 (40.28\%) patients, and hyperlipidemia in $176(35.63 \%)$ patients. In particular, $158(31.98 \%)$ patients were current smokers. Of them, the numbers of patients with UA, NSTEMI, and STEMI were 55 (21.65\%), 18 (29.03\%), and $85(47.75 \%)$, respectively. There was a statistically significant difference in current smoker between three groups $(P<0.0001)$. According to the analysis of underlying diseases by types of ACS, there were statistically significant differences in previous MI $(P=0.0095)$ and PCI $(P<0.0001)$ between three groups.

The results of the analysis of the medications prescribed to ACS patients at discharge are summarized in Table 2. According to the classification of discharge medications by age and sex, aspirin had been most often prescribed compared with other discharge medications. Aspirin was also the discharge medication, which had been most often prescribed in UA, NSTEMI, and STEMI groups.

Table 3 presents the drug regimens used in ACS patients at discharge based on types of ACS. The regimen of aspirin + clopidogrel $+\beta$-blocker + ACE-I/ARB + statin was prescribed to 374 (75.71\%) patients with ACS at discharge. Specifically, this regimen was used in 177 (69.69\%) UA patients, 44 (70.97\%) NSTEMI patients, and 153 (85.96\%) STEMI patients.

Table 4 shows the appropriate prescription of discharge mediations based on age, sex, and types of ACS. Overall, $374(75.71 \%)$ of 494 patients with ACS received all five guideline-recommended medications at discharge from the hospital. When analyzed as the definition of ACS guideline adherence to medication by age, there was a statistically significant difference between guideline adherence and incomplete guideline adherence groups $(P=0.0117)$. Two hundred and fifty-seven $(68.72 \%)$ patients who received all five guideline-recommended drugs were males, and 117 $(31.28 \%)$ were females, and there was a significant difference in sex between guideline adherence and incomplete guideline adherence groups $(P=0.0364)$. The UA, NSTEMI, and STEMI patients with all five guideline-recommended drugs at discharge were 177 (47.33\%), 44 (11.76\%), and $153(40.91 \%)$, respectively, and there was also a significant 


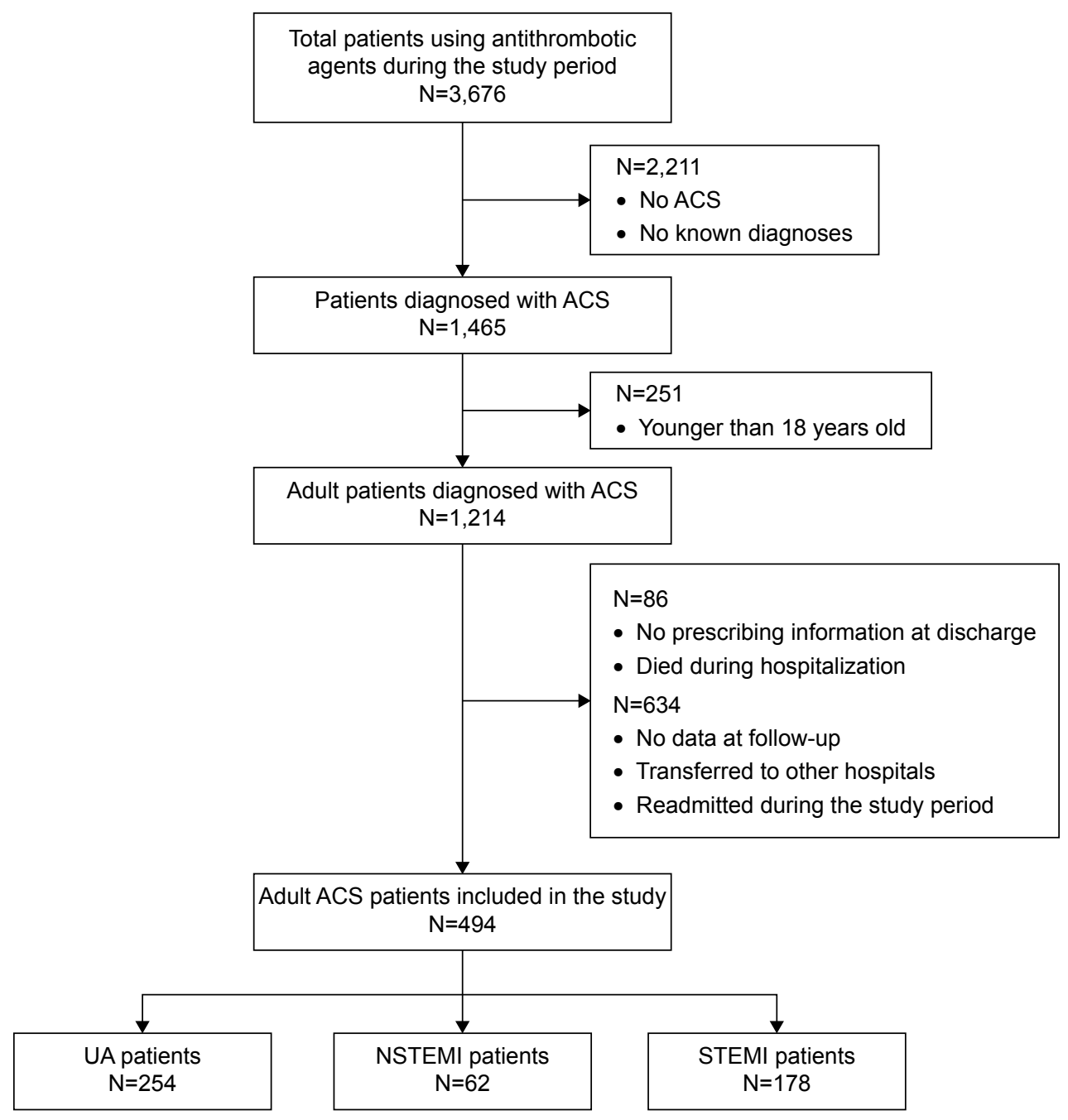

Figure I Flow diagram of steps in the selection of study subjects.

Abbreviations: ACS, acute coronary syndrome; NSTEMI, non-ST-segment elevation myocardial infarction; STEMI, ST-segment elevation myocardial infarction; UA, unstable angina.

difference in types of ACS between guideline adherence and incomplete guideline adherence groups $(P=0.0003)$.

Table 5 summarizes the prescription patterns of secondary prevention medications for ACS at discharge and 3, 6, 12, and 18 months after discharge. Compared with the number of ACS patients with all five guideline-recommended drugs at discharge ( $\mathrm{n}=374,75.71 \%)$, the number of ACS patients using them $12(n=169,34.21 \%)$ and $18(n=105,21.26 \%)$ months after discharge tended to be gradually decreased. In particular, clopidogrel was prescribed to 445 (90.08\%) ACS patients at discharge; however, it was used in 247 (50.00\%) and $173(35.02 \%)$ ACS patients 12 and 18 months after discharge, respectively. Table 6 presents the regimens to be used for the purpose of secondary prevention after ACS at discharge and 3, 6, 12, and 18 months after discharge.

\section{Discussion}

In this study, the guideline adherence to secondary prevention medications for ACS patients at discharge and at 3, 6, 12, and 18 months between September 2009 and August 2013 was investigated. The majority of ACS patients included in this study received all five guideline-recommended medications at discharge from the hospital. However, the frequency of using all of them had been gradually decreased 3, 6, 12, and 18 months after discharge.

Cardiovascular diseases may be increased continuously due to increase in the prevalence of metabolic syndrome over time, since the aging index in Korea is expected to rise from $67.7 \%$ in 2010 to $213.8 \%$ in $2030 .^{24,25}$ Therefore, in Korea, ACS is expected to become one of the most common conditions associated with ischemic heart disease, and ACS-related costs will be likely to increase steadily. It is essential to 
Table I Characteristics of study subjects according to types of ACS

\begin{tabular}{|c|c|c|c|c|c|}
\hline Variable & All patients $(n=494)$ & UA $(n=254)$ & NSTEMI $(n=62)$ & STEMI $(n=\mid 78)$ & $P$-value \\
\hline Age (year), mean $\pm S D$ & $67.71 \pm 10.92$ & $68.17 \pm 10.48$ & $70.69 \pm 10.54$ & $66.01 \pm 11.43$ & 0.0077 \\
\hline$<60, \mathrm{n}(\%)$ & $125(25.30)$ & $55(21.65)$ & $12(19.35)$ & $58(32.58)$ & 0.0106 \\
\hline $60-74, \mathrm{n}(\%)$ & $229(46.36)$ & $128(50.40)$ & $24(38.7 I)$ & $77(43.26)$ & \\
\hline$\geq 75, \mathrm{n}(\%)$ & $140(28.34)$ & 71 (27.95) & $26(41.94)$ & $43(24.16)$ & \\
\hline \multicolumn{6}{|l|}{ Sex } \\
\hline Male, n (\%) & $327(66.19)$ & I 48 (58.27) & $43(69.35)$ & I $36(76.40)$ & 0.0004 \\
\hline Female, n (\%) & $167(33.81)$ & $106(41.73)$ & $19(30.65)$ & $42(23.60)$ & \\
\hline \multicolumn{6}{|l|}{ Demographic characteristics } \\
\hline Height $(\mathrm{cm})$, mean \pm SD & $164.48 \pm 9.08$ & $163.21 \pm 9.17$ & $|59.98 \pm| \mid .37$ & $166.69 \pm 7.88$ & 0.0858 \\
\hline Weight $(\mathrm{kg})$, mean \pm SD & $65.71 \pm 11.96$ & $66.64 \pm 9.6$ & $57.36 \pm 10.43$ & $67.24 \pm 13.28$ & 0.0708 \\
\hline BMI $\left(\mathrm{kg} / \mathrm{m}^{2}\right)$, mean $\pm \mathrm{SD}$ & $24.2 \pm 3.27$ & $25.02 \pm 2.84$ & $22.31 \pm 2.78$ & $24.07 \pm 3.53$ & 0.0718 \\
\hline \multicolumn{6}{|l|}{ Risk factors } \\
\hline Diabetes, n (\%) & $199(40.28)$ & $90(35.43)$ & $31(50.00)$ & $78(43.82)$ & 0.0539 \\
\hline Hypertension, n (\%) & $306(61.94)$ & $170(66.93)$ & $40(64.52)$ & $96(53.93)$ & 0.0213 \\
\hline Hyperlipidemia, n (\%) & $176(35.63)$ & $90(35.43)$ & $32(5 I .6 I)$ & $54(30.34)$ & 0.0107 \\
\hline Renal failure, n (\%) & 38 (7.69) & $13(5.12)$ & 7 (II.29) & $18(10.11)$ & 0.0834 \\
\hline Current smoker, n (\%) & I58 (31.98) & $55(21.65)$ & $18(29.03)$ & $85(47.75)$ & $<0.0001$ \\
\hline Family history, n (\%) & $94(19.03)$ & 45 (I7.72) & $12(19.35)$ & 37 (20.79) & 0.7243 \\
\hline Obesity, n (\%) & I (0.20) & I (0.39) & - & - & 0.6229 \\
\hline \multicolumn{6}{|l|}{ Underlying diseases } \\
\hline Previous MI, n (\%) & $83(16.80)$ & $32(12.60)$ & $9(14.52)$ & $42(23.60)$ & 0.0095 \\
\hline Previous HF, n (\%) & $33(6.68)$ & $16(6.30)$ & $6(9.68)$ & $11(6.18)$ & 0.5993 \\
\hline Previous CABG, $n(\%)$ & II (2.23) & $6(2.36)$ & $2(3.23)$ & $3(1.69)$ & 0.7614 \\
\hline Previous PCl, n (\%) & $443(89.68)$ & $214(84.25)$ & $55(88.7$ I) & 174 (97.75) & $<0.0001$ \\
\hline Previous stroke/TIA, n (\%) & $26(5.26)$ & $9(3.54)$ & $5(8.06)$ & $12(6.74)$ & 0.1956 \\
\hline
\end{tabular}

Abbreviations: ACS, acute coronary syndrome; CABG, coronary artery bypass graft; HF, heart failure; MI, myocardial infarction; NSTEMI, non-ST-segment elevation myocardial infarction; PCl, percutaneous coronary intervention; SD, standard deviation; STEMI, ST-segment elevation myocardial infarction; TIA, transient ischemic attack; UA, unstable angina.

manage ACS early and effectively to prevent ACS-associated mortality and morbidity. According to the ACS guidelines, aspirin, $\beta$-blockers, and statins are recommended for life, whereas ACE-I/ARB should be administered to ACS patients with anterior infarction, $\mathrm{HF}$, or ejection fraction $\leq 40 \%{ }^{4,7,8}$ The ACS guidelines also recommend $\mathrm{P} 2 \mathrm{Y}_{12}$ inhibitors for at least 12 months depending on stents placed. ${ }^{8}$ Since the study on discharge medication patterns and their follow-up assessments after ACS treatment has been rarely conducted in Korea, it is meaningful in that this study could be useful in identifying the gaps between recommended and prescribed ACS medications in Koreans by 18 months from discharge.

Approximately $76 \%$ of ACS patients included in this study received all five guideline-recommended medications at discharge from the hospital. This level was a little higher than those found in other studies. According to the studies

Table 2 Prescription frequency of the five medications for ACS secondary prevention according to the characteristics of study subjects

\begin{tabular}{|c|c|c|c|c|c|}
\hline Variable & Aspirin $(n=485)$ & Clopidogrel $(n=445)$ & ACE-I/ARB $(n=455)$ & $\beta$-Blocker $(n=438)$ & Statin $(n=456)$ \\
\hline Age (year), mean \pm SD & $67.72 \pm 10.99$ & $67.55 \pm 10.86$ & $67.42 \pm 10.9$ & $67.32 \pm 10.74$ & $67.76 \pm 11$ \\
\hline$<60, \mathrm{n}(\%)$ & $124(25.57)$ & II 3 (25.39) & II 8 (25.93) & II 4 (26.03) & $119(26.10)$ \\
\hline $60-74, \mathrm{n}(\%)$ & $221(45.57)$ & $209(46.97)$ & 207 (45.49) & $206(47.03)$ & $214(46.93)$ \\
\hline$\geq 75, \mathrm{n}(\%)$ & $140(28.86)$ & $123(27.64)$ & $130(28.58)$ & II 8 (26.94) & $123(26.97)$ \\
\hline \multicolumn{6}{|l|}{ Sex } \\
\hline Male, n (\%) & $321(66.19)$ & $306(68.76)$ & $303(66.59)$ & $290(66.21)$ & $307(67.32)$ \\
\hline Female, n (\%) & $164(33.81)$ & $139(31.24)$ & $152(33.41)$ & 148 (33.79) & $149(32.68)$ \\
\hline \multicolumn{6}{|l|}{ Types of ACS } \\
\hline UA, n (\%) & $246(50.72)$ & $213(47.87)$ & $229(50.33)$ & $218(49.77)$ & $229(50.22)$ \\
\hline NSTEMI, n (\%) & $6 \mathrm{I}(12.58)$ & $58(13.03)$ & $60(13.19)$ & $52(I I .87)$ & $54(\mathrm{II} .84)$ \\
\hline STEMI, n (\%) & $178(36.70)$ & $174(39.10)$ & $166(36.48)$ & $168(38.36)$ & $173(37.94)$ \\
\hline
\end{tabular}

Abbreviations: ACE-I, angiotensin-converting enzyme inhibitor; ACS, acute coronary syndrome; ARB, angiotensin II receptor blocker; NSTEMI, non-ST-segment elevation myocardial infarction; SD, standard deviation; STEMI, ST-segment elevation myocardial infarction; UA, unstable angina. 
Table 3 Prescription patterns for the five medications for ACS secondary prevention according to types of ACS

\begin{tabular}{|c|c|c|c|c|}
\hline Regimen & All patients $(n=494)$ & UA $(n=254)$ & NSTEMI $(n=62)$ & STEMI $(n=178)$ \\
\hline Aspirin + statin, $\mathrm{n}(\%)$ & $4(0.8 \mathrm{I})$ & $3(1.18)$ & $\mathrm{I}(\mathrm{l} .6 \mathrm{I})$ & - \\
\hline Clopidogrel + statin, n (\%) & $2(0.40)$ & $2(0.79)$ & - & - \\
\hline Aspirin + clopidogrel + statin, $\mathrm{n}(\%)$ & $6(1.21)$ & $3(1.18)$ & - & $3(1.69)$ \\
\hline Aspirin $+\beta$-blocker, $\mathrm{n}(\%)$ & I $(0.20)$ & I (0.39) & - & - \\
\hline Aspirin + clopidogrel $+\beta$-blocker, $n(\%)$ & $2(0.40)$ & I (0.39) & - & I (0.56) \\
\hline Aspirin + ACE-I/ARB, $n(\%)$ & $5(1.01)$ & $4(1.57)$ & $\mathrm{I}(\mathrm{I} .6 \mathrm{I})$ & - \\
\hline Aspirin + clopidogrel + ACE-I/ARB, $n(\%)$ & $2(0.40)$ & I (0.39) & $\mathrm{I}(\mathrm{I} .6 \mathrm{I})$ & - \\
\hline Aspirin $+\beta$-blocker + statin, $n(\%)$ & $4(0.81)$ & $4(1.57)$ & - & - \\
\hline Aspirin + clopidogrel $+\beta$-blocker + statin, $n(\%)$ & $16(3.24)$ & $7(2.76)$ & $\mathrm{I}(1.6 \mathrm{I})$ & $8(4.49)$ \\
\hline Aspirin + ACE-I/ARB + statin, $n(\%)$ & $7(1.42)$ & $6(2.36)$ & - & $\mathrm{I}(0.56)$ \\
\hline Clopidogrel + ACE-I/ARB + statin, $n$ (\%) & $2(0.40)$ & $2(0.79)$ & - & - \\
\hline Aspirin + clopidogrel + ACE-I/ARB + statin, n (\%) & $25(5.06)$ & $12(4.72)$ & 7 (II.29) & $6(3.37)$ \\
\hline Aspirin $+\beta$-blocker + ACE-I/ARB + statin, $n(\%)$ & $15(3.04)$ & $13(5.12)$ & - & $2(1.12)$ \\
\hline Aspirin + clopidogrel $+\beta$-blocker + ACE-I/ARB + statin, $n(\%)$ & $374(75.71)$ & 177 (69.69) & $44(70.97)$ & $153(85.96)$ \\
\hline
\end{tabular}

Abbreviations: ACE-I, angiotensin-converting enzyme inhibitor; ACS, acute coronary syndrome; ARB, angiotensin II receptor blocker; NSTEMI, non-ST-segment elevation myocardial infarction; STEMI, ST-segment elevation myocardial infarction; UA, unstable angina.

conducted in the Netherlands, about $65 \%$ and $69 \%$ of ACS patients were discharged with the guideline-recommended medications for ACS secondary prevention. ${ }^{20,23}$ The study conducted in Australia and New Zealand also reported that the rate of ACS patients discharged on secondary prevention medications was about $71 \% .{ }^{26}$ However, this study applied the different definition about an optimal medication therapy for secondary prevention after ACS. It was defined as prescribing any four mediations of the following: aspirin, other antiplatelet, ACE-I/ARB, $\beta$-blocker, or statin/lipidlowering agent. ${ }^{26}$ Consequently, if the definition used in our study was applied, the rate may be expected to be lower than observed. In particular, patients with NSTEMI showed much lower rates of prescription compared with patients with UA and STEMI, which was similar to the results of the Taiwan Acute Coronary Syndrome Descriptive Registry. ${ }^{27}$ This could suggest that the treating physicians had a lower perception to detect disease severity in case of NSTEMI.

As a result of the 18-month follow-up evaluation of discharge medications recommended by the latest guidelines for ACS secondary prevention, the frequency of using all five guideline-recommended discharge medications had been gradually decreased 3,6,12, and 18 months after discharge compared with that at discharge. Specifically, the frequency of prescribing them was reduced to about one-half after 12 months and to about one-third after 18 months compared with that at discharge. This result is similar to that from the prospective follow-up study conducted by $\mathrm{Bi}$ et al, ${ }^{13}$ in which the frequency of using the discharge medications was decreased 6 and 12 months after discharge. The prescription rate of clopidogrel declined from $90.08 \%$ at discharge to $50.00 \%$ at 12 months and to $35.02 \%$ at 18 months. This result

Table 4 Appropriateness of discharge medications for ACS secondary prevention according to the characteristics of study subjects

\begin{tabular}{|c|c|c|c|c|}
\hline Variable & All patients $(n=494)$ & Guideline adherence $(n=374)$ & Incomplete guideline adherence $(n=\mid 20)$ & $P$-value \\
\hline Age (year), mean \pm SD & $67.71 \pm 10.92$ & $70.23 \pm 10.45$ & $66.90 \pm 10.96$ & 0.0044 \\
\hline$<60, \mathrm{n}(\%)$ & $125(25.30)$ & $106(28.34)$ & $19(15.83)$ & 0.0117 \\
\hline $60-74, \mathrm{n}(\%)$ & $229(46.36)$ & I7I (45.72) & $58(48.33)$ & \\
\hline$\geq 75, \mathrm{n}(\%)$ & I 40 (28.34) & $97(25.94)$ & $43(35.83)$ & \\
\hline \multicolumn{5}{|l|}{ Sex } \\
\hline Male, n (\%) & $327(66.19)$ & $257(68.72)$ & $70(58.33)$ & 0.0364 \\
\hline Female, n (\%) & I $67(33.8 \mathrm{I})$ & $117(31.28)$ & $50(4 I .67)$ & \\
\hline \multicolumn{5}{|l|}{ Types of ACS } \\
\hline UA, n (\%) & $254(51.42)$ & $177(47.33)$ & $77(64.17)$ & 0.0003 \\
\hline NSTEMI, n (\%) & $62(12.55)$ & $44(11.76)$ & $18(15.00)$ & \\
\hline STEMI, n (\%) & I 78 (36.03) & I53 (40.9I) & $25(20.83)$ & \\
\hline
\end{tabular}

Note: Guideline adherence indicates that all five drugs (ie, aspirin, $P 2 Y_{12}$ receptor inhibitor, statin, $\beta$-blocker, and ACE-I/ARB) were prescribed to patients discharged after ACS treatment.

Abbreviations: ACE-I, angiotensin-converting enzyme inhibitor; ACS, acute coronary syndrome; ARB, angiotensin II receptor blocker; NSTEMI, non-ST-segment elevation myocardial infarction; SD, standard deviation; STEMI, ST-segment elevation myocardial infarction; UA, unstable angina. 
Table 5 Prescription frequency of the five medications for ACS secondary prevention at discharge and 3, 6, I2, and I8 months after discharge

\begin{tabular}{|c|c|c|c|c|c|}
\hline Variable & At discharge, $(n=494)$ & 3-month f/u, $(n=494)$ & 6-month f/u, $(n=494)$ & I2-month f/u, (n=494) & I8-month f/u, $(n=494)$ \\
\hline Aspirin, n (\%) & $485(98.18)$ & $448(90.69)$ & $476(96.36)$ & $478(96.76)$ & $480(97.17)$ \\
\hline Clopidogrel, n (\%) & $445(90.08)$ & $363(73.48)$ & $331(67.00)$ & $247(50.00)$ & $173(35.02)$ \\
\hline ACE-I/ARB, n (\%) & $455(92.11)$ & $385(77.94)$ & $395(79.96)$ & $394(79.76)$ & $387(78.34)$ \\
\hline$\beta$-Blocker, n (\%) & $438(88.66)$ & $392(79.35)$ & $4 I I(83.20)$ & $40 I(81.17)$ & $394(79.76)$ \\
\hline Statin, n (\%) & $456(92.3 \mathrm{I})$ & $40 I(8 I .17)$ & $418(84.62)$ & $425(86.03)$ & $425(86.03)$ \\
\hline All five drugs, n (\%) & $374(75.7 I)$ & $25 \mathrm{I}(50.8 \mathrm{I})$ & $229(46.36)$ & $169(34.21)$ & $105(21.26)$ \\
\hline
\end{tabular}

Note: All five drugs include aspirin, $\mathrm{P} 2 \mathrm{Y}_{12}$ receptor inhibitor, ACE-I/ARB, $\beta$-blocker, and statin.

Abbreviations: ACE-I, angiotensin-converting enzyme inhibitor; ACS, acute coronary syndrome; ARB, angiotensin II receptor blocker; f/u, follow-up.

was similar to that of the Taiwan Acute Coronary Syndrome Descriptive Registry, wherein Cheng et a ${ }^{27}$ reported that the prescription rate of aspirin and clopidogrel rapidly decreased from $61.8 \%$ at discharge to $12.6 \%$ at 12 months. They also reported physician's judgment as the most common reason to discontinue clopidogrel. ${ }^{27}$ However, this study could not observe the causes of clopidogrel discontinuation due to limited authority of pharmacists to access the EMRs of patients.

The use of antithrombotic agents is recommended in order to reduce the rates of morbidity and mortality in patients with ACS. In this study, aspirin was an antithrombotic agent most frequently prescribed during the hospitalization followed by clopidogrel (93.93\%) and enoxaparin (71.40\%). In particular, compared with unfractionated heparin, enoxaparin has more predictable anticoagulant effects, better bioavailability, longer half-life, and less frequent laboratory monitoring so that enoxaparin has more advantages over unfractionated heparin in the treatment for ACS. ${ }^{28}$ However, in spite of these benefits from using enoxaparin, its most important side effect is associated with bleeding complications. ${ }^{28}$ For example, potentially fatal bleeding complications such as spontaneous retroperitoneal hematoma may occur in case of administering enoxaparin to patients with reduced renal functions..$^{29}$ Thus, it is necessary to carefully monitor side effects from enoxaparin as well as antiplatelet agents.

However, despite more improved management of ACS with antiplatelet and anticoagulant agents, a number of ACS patients keep suffering from the recurrence of ischemic cardiovascular events, which has contributed to the development of novel antithrombotic agents in order to more efficiently inhibit the formation of coronary thrombus. ${ }^{30-33}$ These novel agents targeting thrombin-mediated pathways consist of direct Xa inhibitors (apixaban, rivaroxaban, and darexaban), direct thrombin inhibitors (dabigatran), and protease-activated receptor 1 antagonists (vorapaxar

Table 6 Prescription patterns for the five medications for ACS secondary prevention at discharge and 3, 6, I2, and I8 months after discharge

\begin{tabular}{|c|c|c|c|c|c|}
\hline Regimen & $\begin{array}{l}\text { At discharge, } \\
(n=494)\end{array}$ & $\begin{array}{l}\text { 3-month f/u, } \\
(n=494)\end{array}$ & $\begin{array}{l}\text { 6-month f/u, } \\
(n=494)\end{array}$ & $\begin{array}{l}\text { I 2-month f/u, } \\
(n=494)\end{array}$ & $\begin{array}{l}\text { I 8-month f/u, } \\
(n=494)\end{array}$ \\
\hline Aspirin + statin, n (\%) & $4(0.8 I)$ & $5(\mathrm{I} .0 \mathrm{I})$ & $8(1.62)$ & $12(2.43)$ & $14(2.83)$ \\
\hline Clopidogrel + statin, n (\%) & $2(0.40)$ & - & - & - & - \\
\hline Aspirin + clopidogrel + statin, n (\%) & $6(1.2 \mid)$ & $5(1.01)$ & $6(1.21)$ & $4(0.8 I)$ & $5(1.01)$ \\
\hline Aspirin $+\beta$-blocker, $\mathrm{n}(\%)$ & I $(0.20)$ & $4(0.8 I)$ & $5(1.01)$ & $5(1.01)$ & $5(1.01)$ \\
\hline Aspirin + clopidogrel + $\beta$-blocker, n (\%) & $2(0.40)$ & $3(0.6 I)$ & $4(0.8 I)$ & $3(0.6 I)$ & $5(1.01)$ \\
\hline Aspirin + ACE-I/ARB, n (\%) & $5(1.01)$ & $2(0.40)$ & $5(1.01)$ & $7(1.42)$ & $7(1.42)$ \\
\hline Clopidogrel + ACE-I/ARB, n (\%) & - & - & - & I $(0.20)$ & I $(0.20)$ \\
\hline Aspirin + clopidogrel + ACE-I/ARB, n (\%) & $2(0.40)$ & $2(0.40)$ & $3(0.6 I)$ & $3(0.6 I)$ & $3(0.6 I)$ \\
\hline Aspirin $+\beta$-blocker + statin, $\mathrm{n}(\%)$ & $4(0.81)$ & $17(3.44)$ & $27(5.47)$ & $44(8.91)$ & $52(10.53)$ \\
\hline Aspirin + clopidogrel $+\beta$-blocker + statin, $n(\%)$ & $16(3.24)$ & $34(6.88)$ & $32(6.48)$ & $18(3.64)$ & $18(3.64)$ \\
\hline Aspirin + ACE-I/ARB + statin, n (\%) & $7(1.42)$ & $17(3.44)$ & $21(4.25)$ & 35 (7.09) & $48(9.72)$ \\
\hline Clopidogrel + ACE-I/ARB + statin, n (\%) & $2(0.40)$ & - & - & - & - \\
\hline Aspirin + clopidogrel + ACE-I/ARB + statin, n (\%) & $25(5.06)$ & $28(5.67)$ & $21(4.25)$ & $15(3.04)$ & $12(2.43)$ \\
\hline Aspirin + $\beta$-blocker + ACE-I/ARB + statin, n (\%) & $15(3.04)$ & $38(7.69)$ & $71(14.37)$ & $123(24.90)$ & $163(33.00)$ \\
\hline Clopidogrel + $\beta$-blocker + ACE-I/ARB + statin, n (\%) & - & $2(0.40)$ & - & - & $3(0.61)$ \\
\hline Aspirin + clopidogrel + $\beta$-blocker + ACE-I/ARB + statin, n (\%) & $374(75.7 I)$ & $25 I(50.8 I)$ & $229(46.36)$ & $169(34.21)$ & $105(21.26)$ \\
\hline
\end{tabular}

Abbreviations: ACE-I, angiotensin-converting enzyme inhibitor; ACS, acute coronary syndrome; ARB, angiotensin II receptor blocker; f/u, follow-up. 
and atopaxar). ${ }^{30}$ The concept of ACS follow-up management using a novel oral anticoagulant (NOAC) together with standard antithrombotic therapy including aspirin and P2 $Y_{12}$ inhibitor may be expected to reduce the rate of future ischemic cardiovascular events. ${ }^{32-34}$ However, as shown in some clinical trials, ${ }^{35-39}$ adding a NOAC to standard antithrombotic therapy after ACS has led to modest reduction of ischemic events, but it has consistently caused increases in bleeding complications. Therefore, before using NOACs for ACS follow-up management, whether the clinical benefit outweighs the risk should be evaluated.

Our study has some limitations which should be mentioned. All necessary data for the analysis were retrospectively collected through the review of electronic patients' medical charts, and the appropriateness of secondary prevention drug therapy for ACS was determined based on all five guideline-recommended medications prescribed most closely to $3,6,12$, and 18 months after discharge. Therefore, this could affect assessment of the appropriate medical therapy for secondary prevention after ACS. In this study, only prescription patterns of discharge medications and their appropriateness in ACS patients were investigated, so it is necessary to conduct more studies regarding the outcomes, such as changes in laboratory parameters, of ACS patients according to the prescription patterns of discharge medications for ACS in the near future.

\section{Conclusion}

The American Heart Association/American College of Cardiology guidelines for ACS recommend the long-term administration of aspirin, $\mathrm{P} 2 \mathrm{Y}_{12}$ inhibitor, ACE-I/ARB, $\beta$-blocker, and statin from discharge to reduce recurrence of ischemic cardiovascular events and to improve the quality of life in patients with ACS. In this study, we examined the prescription patterns of these medications from discharge to 18 months after discharge. The majority of ACS patients included in this study received all five guideline-recommended medications at discharge from the hospital. However, the frequency of using all of them had been gradually decreased 3, 6, 12, and 18 months after discharge compared with that at discharge. It is also necessary to perform more studies about the outcomes of ACS patients according to the prescription patterns of those medications for ACS secondary prevention in the near future.

\section{Acknowledgment}

This study was supported by a research fund from Chosun University, 2015.

\section{Disclosure}

The authors report no conflicts of interest in this work.

\section{References}

1. Huber K, Bates ER, Valgimigli M, et al. Antiplatelet and anticoagulant agents in acute coronary syndromes: what is the current status and what does the future hold? Am Heart J. 2014;168:611-621.

2. Aronow WS. Treatment of unstable angina pectoris/non-ST-segment elevation myocardial infarction in elderly patients. J Gerontol A Biol Sci Med Sci. 2003;58:M927-M933.

3. Smith JN, Negrelli JM, Manek MB, Hawes EM, Viera AJ. Diagnosis and management of acute coronary syndrome: an evidence-based update. J Am Board Fam Med. 2015;28:283-293.

4. Amsterdam EA, Wenger NK, Brindis RG, et al. 2014 AHA/ACC guideline for the management of patients with non-ST-elevation acute coronary syndromes: a report of the American College of Cardiology/ American Heart Association Task Force on Practice Guidelines. $J$ Am Coll Cardiol. 2014;64:e139-e228.

5. Tra J, Engel J, van der Wulp I, de Bruijne MC, Wagner C. Monitoring guideline adherence in the management of acute coronary syndrome in hospitals: design of a multicentre study. Neth Heart $J$. 2014;22:346-353.

6. Hassan Y, Kassab Y, Abd Aziz N, Akram H, Ismail O. The impact of pharmacist-initiated interventions in improving acute coronary syndrome secondary prevention pharmacotherapy prescribing upon discharge. J Clin Pharm Ther. 2013;38:97-100.

7. Huber K, Gersh BJ, Goldstein P, Granger CB, Armstrong PW. The organization, function, and outcomes of ST-elevation myocardial infarction networks worldwide: current state, unmet needs and future directions. Eur Heart J. 2014;35:1526-1532.

8. O'Gara PT, Kushner FG, Ascheim DD, et al. 2013 ACCF/AHA guideline for the management of ST-elevation myocardial infarction: a report of the American College of Cardiology Foundation/American Heart Association Task Force on Practice Guidelines. J Am Coll Cardiol. 2013;61:e78-e140.

9. Jäger B, Farhan S, Kalla K, et al. One-year mortality in patients with acute ST-elevation myocardial infarction in the Vienna STEMI registry. Wien Klin Wochenschr. 2015;127:535-542.

10. Yusuf $\mathrm{S}$. Two decades of progress in preventing vascular disease. Lancet. 2002;360:2-3.

11. Allonen J, Nieminen MS, Lokki M, et al. Mortality rate increases steeply with nonadherence to statin therapy in patients with acute coronary syndrome. Clin Cardiol. 2012;35:E22-E27.

12. Yan AT, Yan RT, Tan M, et al. Optimal medical therapy at discharge in patients with acute coronary syndromes: temporal changes, characteristics, and 1-year outcome. Am Heart J. 2007;154:1108-1115.

13. Bi Y, Gao R, Patel A, et al. Evidence-based medication use among Chinese patients with acute coronary syndromes at the time of hospital discharge and 1 year after hospitalization: results from the Clinical Pathways for Acute Coronary Syndromes in China (CPACS) study. Am Heart J. 2009;157:509.e1-516.e1.

14. Gurm HS, Eagle KA. Use of anticoagulants in ST-segment elevation myocardial infarction patients: a focus on low-molecular-weight heparin. Cardiovasc Drugs Ther. 2008;22:59-69.

15. Lee HY, Cooke CE, Robertson TA. Use of secondary prevention drug therapy in patients with acute coronary syndrome after hospital discharge. J Manag Care Pharm. 2008;14:271-280.

16. Doyle F, De La Harpe D, McGee H, Shelley E, Conroy R. Gender differences in the presentation and management of acute coronary syndromes: a national sample of 1365 admissions. Eur J Cardiovasc Prev Rehabil. 2005;12:376-379.

17. Birkhead JS, Weston C, Lowe D. Impact of specialty of admitting physician and type of hospital on care and outcome for myocardial infarction in England and Wales during 2004-5: observational study. BMJ. 2006;332:1306-1311. 
18. Danchin N, Cambou JP, Hanania G, et al. Impact of combined secondary prevention therapy after myocardial infarction: data from a nationwide French registry. Am Heart J. 2005;150:1147-1153.

19. van der Elst ME, Bouvy ML, de Blaey CJ, de Boer A. Effect of drug combinations on admission for recurrent myocardial infarction. Heart. 2007;93:1226-1230

20. Tra J, van der Wulp I, Appelman Y, de Bruijne MC, Wagner C. Adherence to guidelines for the prescription of secondary prevention medication at hospital discharge after acute coronary syndrome: a multicenter study. Neth Heart J. 2015;23:214-221.

21. Chen HY, Saczynski JS, Lapane KL, Kiefe CI, Goldberg RJ. Adherence to evidence-based secondary prevention pharmacotherapy in patients after an acute coronary syndrome: a systematic review. Heart Lung. 2015;44:299-308.

22. Vermeer NS, Bajorek BV. Utilization of evidence-based therapy for the secondary prevention of acute coronary syndromes in Australian practice. J Clin Pharm Ther. 2008;33:591-601.

23. Yetgin T, van der Linden MM, de Vries AG, et al. Current discharge management of acute coronary syndromes: data from the Rijnmond Collective Cardiology Research (CCR) study. Neth Heart J. 2014;22:20-27.

24. Kim J, Lee E, Lee T, Sohn A. Economic burden of acute coronary syndrome in South Korea: a national survey. BMC Cardiovasc Disord. 2013;13:55.

25. Moebus S, Balijepalli C, Lösch C, et al. Age- and sex-specific prevalence and ten-year risk for cardiovascular disease of all 16 risk factor combinations of the metabolic syndrome: a cross-sectional study. Cardiovasc Diabetol. 2010;9:34

26. Redfern J, Hyun K, Chew DP, et al. Prescription of secondary prevention medications, lifestyle advice, and referral to rehabilitation among acute coronary syndrome inpatients: results from a large prospective audit in Australia and New Zealand. Heart. 2014;100:1281-1288.

27. Cheng CI, Chen CP, Kuan PL, et al. The causes and outcomes of inadequate implementation of existing guidelines for antiplatelet treatment in patients with acute coronary syndrome: the experience from Taiwan Acute Coronary Syndrome Descriptive Registry (T-ACCORD Registry). Clin Cardiol. 2010;33:E40-E48.

28. Jinatongthai $\mathrm{P}$, Khaisombut N, Likittanasombat K, Chaiyakunapruk N, Watcharathanakij S, Nathisuwan S. Use of the CRUSADE bleeding risk score in the prediction of major bleeding for patients with acute coronary syndrome receiving enoxaparin in Thailand. Heart Lung Circ. 2014;23:1051-1058
29. Salemis NS, Oikonomakis I, Lagoudianakis E, et al. Enoxaparin-induced spontaneous massive retroperitoneal hematoma with fatal outcome. Am J Emerg Med. 2014;32:1559.e1-e3.

30. Costopoulos C, Niespialowska-Steuden M, Kukreja N, Gorog DA. Novel oral anticoagulants in acute coronary syndrome. Int J Cardiol. 2013;167:2449-2455.

31. De Caterina R, Husted S, Wallentin L, et al. New oral anticoagulants in atrial fibrillation and acute coronary syndromes: ESC working group on thrombosis-task force on anticoagulants in heart disease position paper. J Am Coll Cardiol. 2012;59:1413-1425.

32. Deftereos S, Bouras G, Giannopoulos G, et al. Novel oral anticoagulants in the treatment of acute coronary syndromes: is there any room for new anticoagulants? Curr Clin Pharmacol. 2012;7:195-208.

33. Alfredsson J, Roe MT. Risks and benefits of triple oral anti-thrombotic therapies after acute coronary syndromes and percutaneous coronary intervention. Drug Saf. 2015;38:481-491.

34. Ganetsky VS, Hadley DE, Thomas TF. Role of novel and emerging oral anticoagulants for secondary prevention of acute coronary syndromes. Pharmacotherapy. 2014;34:590-604.

35. Alexander JH, Lopes RD, James S, et al. Apixaban with antiplatelet therapy after acute coronary syndrome. $N$ Engl $\mathrm{J} \mathrm{Med}$. 2011;365:699-708.

36. Mega JL, Braunwald E, Wiviott SD, et al. Rivaroxaban in patients with a recent acute coronary syndrome. $N$ Engl J Med. 2012;366:9-19.

37. Steg PG, Mehta SR, Jukema JW, et al. RUBY-1: a randomized, doubleblind, placebo-controlled trial of the safety and tolerability of the novel oral factor Xa inhibitor darexaban (YM150) following acute coronary syndrome. Eur Heart J. 2011;32:2541-2554.

38. Oldgren J, Budaj A, Granger CB, et al. Dabigatran vs. placebo in patients with acute coronary syndromes on dual antiplatelet therapy: a randomized double-blind, phase II trial. Eur Heart J. 2011;32:2781-2789.

39. Tricoci P, Huang Z, Held C, et al. Thrombin-receptor antagonist vorapaxar in acute coronary syndromes. $N$ Engl J Med. 2012;366:20-33.
Therapeutics and Clinical Risk Management

\section{Publish your work in this journal}

Therapeutics and Clinical Risk Management is an international, peerreviewed journal of clinical therapeutics and risk management, focusing on concise rapid reporting of clinical studies in all therapeutic areas, outcomes, safety, and programs for the effective, safe, and sustained use of medicines. This journal is indexed on PubMed Central, CAS,

\section{Dovepress}

EMBase, Scopus and the Elsevier Bibliographic databases. The manuscript management system is completely online and includes a very quick and fair peer-review system, which is all easy to use. Visit http://www.dovepress.com/testimonials.php to read real quotes from published authors. 